
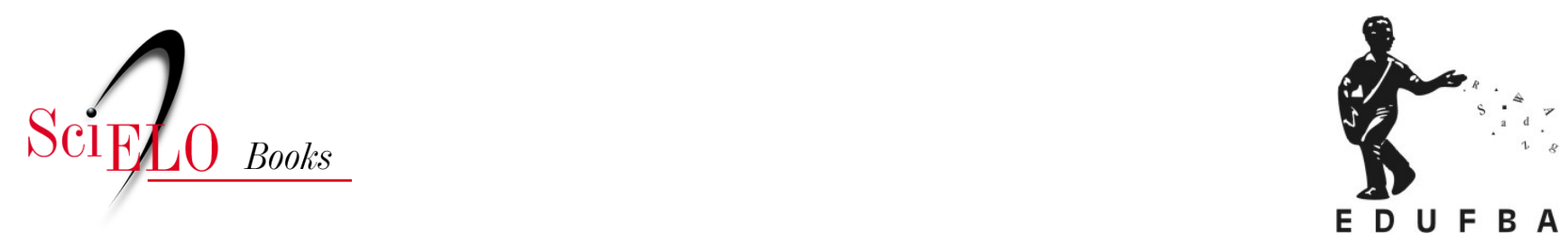

\title{
Trabalho e distúrbios musculoesqueléticos na limpeza urbana
}

\author{
Adilton Luiz Pio Pereira \\ Rita de Cássia Pereira Fernandes
}

\section{SciELO Books / SciELO Livros / SciELO Libros}

PEREIRA, A.L.P., and FERNANDES, R.C.P. Trabalho e distúrbios musculoesqueléticos na limpeza urbana. In: FERNANDES, R.C.P., LIMA, M.A.G., and ARAÚJO, T.M., comps. Tópicos em saúde, ambiente e trabalho: um olhar ampliado [online]. Salvador: EDUFBA, 2014, pp. 103-128. ISBN: 97865-5630-012-2. https://doi.org/10.7476/9786556300122.0007.

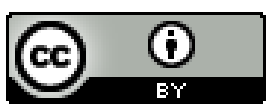

All the contents of this work, except where otherwise noted, is licensed under a Creative Commons Attribution 4.0 International license.

Todo o conteúdo deste trabalho, exceto quando houver ressalva, é publicado sob a licença Creative Commons Atribição 4.0. 


\section{Trabalho e distúrbios musculoesqueléticos na limpeza urbana}

Adilton Luiz Pio Pereira

Rita de Cássia Pereira Fernandes

\section{Introdução}

Os Distúrbios Musculoesqueléticos (DME) são um dos problemas mais frequentes e mais dispendiosos em todo o mundo, configurando-se como importante doença relacionada ao trabalho em todos os países, independente do seu grau de industrialização. Nos Estados Unidos, aproximadamente um milhão de pessoas, a cada ano, relata afastar-se do trabalho para tratar ou recuperar-se de dor musculoesquelética. (NATIONAL RESEARCH COUNCIL; INSTITUTE OF MEDICINE, 2001; BRANDÃO; HORTA; TOMASI, 2005; MARRAS et al., 2009) Dados da Previdência Social no Brasil (2010) mostram que os DME mais prevalentes, no ano de 2009 , foram as lesões no ombro, no dorso e em membros superiores, com 19,7\%, 13,1\% e 9,5\%, respectivamente.

Os DME são caracterizados por

diversos sinais e sintomas de desordens inflamatórias e/ou degenerativas que acometem tendões, nervos, músculos, articulações, circulação e bursas, e resultam principalmente em dor e incapacidade funcional. (MAGNAGO et al. 2010)

Os DME são multicausais, de diagnóstico e estabelecimento de nexo causal com o trabalho mais complexo e nem sempre claro, necessitam de múltiplas abordagens, que não só tratem os sintomas, mas que interfiram nos aspectos ambientais, organizacionais e nas relações de trabalho, implicados na sua causalidade. 
Estudos têm demonstrado que há uma relação entre DME e demanda física no trabalho, além disso, alguns estudos fornecem também suporte à associação entre DME e demanda psicossocial no trabalho. $\mathrm{O}$ efeito dos fatores psicossociais para DME pode ser, em parte ou inteiramente, independente de fatores físicos. (NATIONAL RESEARCH COUNCIL; INSTITUTE OF MEDICINE, 2001; PUNNETT; WEGMAN, 2004; COSTA; VIEIRA, 2009)

De acordo com revisão sistemática conduzida pelo National Research Council - NRC e Institute of Medicine - IM (2001), os estudos para DME em extremidades superiores evidenciaram forte associação desses com a alta demanda psicológica e o baixo suporte social. Revisão de literatura feita por Woods (2005) também constatou evidências de associação entre DME e baixo suporte social. Os mecanismos pelos quais o suporte social influencia o sistema musculoesquelético ainda não estão claros, porém acredita-se que um ambiente de trabalho colaborativo pode dar aos trabalhadores melhor oportunidade de lidar com o sofrimento e, dessa forma, prevenir o surgimento de dores mais severas. $\mathrm{Na}$ atividade de coleta de resíduo sólido, os colegas podem fornecer ajuda ao trabalhador no manuseio de carga e com isso diminuir os sintomas musculoesqueléticos.

Algumas características individuais e exposições não ocupacionais podem ser incluídas como variáveis associadas aos DME, como: a idade, o consumo de bebida alcoólica, características antropométricas, hábito de fumar e atividade física. (KUORINKA; FORCIER, 1995)

Diversos estudos no Brasil têm destacado a elevada morbidade por DME em profissionais das áreas de serviço e indústria. (CARDOSO et al., 2009, GRAÇA; ARAÚJO; SILVA, 2006; PICOLOTO; SILVEIRA, 2008, FERNANDES; CARVALHO; ASSUNÇÃO, 2011) Isso destaca a importância do tema para a saúde coletiva e para a vigilância epidemiológica dos DME.

Considerando a importância dos DME como problema de saúde pública, definiu-se pela realização de um estudo sobre esse problema em trabalhadores de limpeza urbana. A escolha desses trabalhadores foi motivada pela presença marcante de fatores de risco para DME já descritos na literatura, nos processos de trabalho e na limpeza urbana, pelo relato de busca de serviço de saúde por trabalhadores de limpeza urbana com quadros de DME. Em revisão da literatura nacional, não 
foram encontrados estudos epidemiológicos sobre DME em trabalhadores da limpeza urbana.

Assim, foi conduzido este estudo com o objetivo de estimar a prevalência de DME, descrever as características ocupacionais na limpeza urbana na cidade de Salvador e identificar os fatores associados ao agravo.

\section{O trabalho na limpeza urbana em Salvador}

A cidade de Salvador está situada na Região Nordeste do Brasil, ocupa uma área de $313 \mathrm{~km} 2$ (sendo $283 \mathrm{~km} 2$ no continente e $30 \mathrm{~km} 2$ nas Ilhas). O sistema de limpeza urbana e manejo de resíduos sólidos nesta cidade são geridos pela Secretaria Municipal de Serviços Públicos e Prevenção à Violência - SESP. O sistema operacional é composto pela Empresa de Limpeza Urbana de Salvador - LIMPURB, empresa pública responsável pela definição de políticas, fiscalização e controle dos serviços, cadastro das empresas privadas transportadoras de resíduos de responsabilidade do gerador, limpeza das praças e jardins, e por uma empresa concessionária, responsável pela implantação, operação e manutenção do Aterro Sanitário Metropolitano Centro e Estação de Transbordo. O sistema conta ainda com os serviços de uma empresa responsável pela instalação de sanitários portáteis químicos; com um Consórcio, formado por quatro empresas responsável pela execução dos serviços de limpeza urbana. Criada, embora ainda não regulamentada, há a Agência Reguladora e Fiscalizadora dos Serviços de Limpeza Urbana e Manejo de Resíduos Sólidos de Salvador - ARSAL. O custeio dos serviços de limpeza urbana é de responsabilidade do Fundo Municipal de Limpeza Urbana - FMLU. (BAHIA, 2012)

A operação dos serviços de limpeza urbana e manejo de resíduos sólidos no município de Salvador, realizada pelas empresas terceirizadas, são de vasta abrangência e incorporam os serviços especiais de limpeza urbana, a varrição de vias e logradouros públicos, a limpeza urbana e manejo de resíduos sólidos em áreas de difícil acesso, a limpeza de praias, a limpeza urbana e manejo de resíduos sólidos em lagoas e espelhos d'água, a coleta e transporte de resíduos sólidos domiciliares, a coleta e transporte de resíduos de construção e demolição, a limpeza urbana e manejo de resíduos sólidos nas Ilhas de Maré, Bom Jesus e 
dos Frades, o transporte de materiais recicláveis, a lavagem de vias e logradouros públicos, a educação ambiental, a operação carnaval, a operação chuva e a operação dengue. (BAHIA, 2012)

Apesar da legislação existente e da formalização de sistemas de gestão da limpeza urbana, além do fato da produção, disposição e coleta de lixo, e suas implicações sobre o meio ambiente e a saúde da população já serem amplamente discutidos na literatura, os aspectos relacionados à saúde e bem-estar dos trabalhadores de limpeza urbana ainda são pouco estudados.

Segundo Velloso (2008), desde a idade média, o lixo esteve associado com as palavras "praga", "peste" ou "pestilência", significando algo que produzia um alto índice de mortalidade. Somente a partir de 1970, o lixo passou a ser considerado como um problema ambiental. A visão de que o lixo está associado a enfermidades continua até o momento presente, ao tempo em que se mantém a discriminação dos trabalhadores que são responsáveis pelo seu manuseio e destinação final.

No Brasil, esses trabalhadores estão acostumados a ser chamados de "garis". A origem deste nome teve início no século XX, na época em que os serviços de limpeza urbana eram feitos pelos Irmãos Garys, da Companhia Industrial do Rio de Janeiro, que desempenhava os serviços de coleta, transporte e destino final do lixo. (VELLOSO, 2008)

Esses trabalhadores, em geral, são invisíveis para a sociedade, apesar da importância social do seu labor. Velloso (2008) relata a experiência do psicólogo social Fernando Braga da Costa que revelou esta invisibilidade do coletor do lixo quando, no curso de um projeto acadêmico, travestido de gari, realizou a varrição de ruas no campus da Universidade de São Paulo, com o objetivo de abordar a percepção humana condicionada à divisão social do trabalho. O estudo permitiu afirmar, no contexto abordado, que as pessoas enxergam mais o resultado do trabalho e menos os sujeitos humanos que o executam. (VELLOSO, 2008)

A atividade de limpeza urbana faz parte dos serviços não exclusivos do Estado, ou seja, aqueles que ele provê, mas que podem ser oferecidos pelo setor privado e pelo setor público não estatal. Porém, ao terceirizar essa atividade, o Estado também terceiriza a gestão da força de trabalho e privatiza as relações de trabalho e com isso há uma perda da autonomia e do controle que o trabalhador exerce sobre sua própria 
atividade, fazendo com que apareçam situações que podem levar ao seu adoecimento. (SANTOS et al., 2009)

Os estudos sobre terceirização trazem o consenso quanto à precarização do trabalho e à fragilização social do trabalhador. Há evidência de redução salarial, perda de direitos trabalhistas e intensificação do trabalho, assim como má condição de saúde do trabalhador, refletida pelo grande número de acidentes e adoecimento físico e mental. (ARAÚJO, 2001; DRUCK, 2011)

O trabalho de limpeza urbana é muito complexo e apresenta características próprias como: a variabilidade da produção e do ambiente, a variabilidade do tempo, as questões de segurança e uso propriamente do corpo. Para a realização da sua atividade, o trabalhador passa a desenvolver competências específicas e passa a adotar estratégias de regulação, pois sua atividade se desenvolve em condições não controladas, como: trânsito urbano, intempéries, relação com a população, panes dos equipamentos. (VASCONCELOS et al., 2008; CAMADA; PATARO; FERNANDES, 2012)

Os trabalhadores que fazem a coleta do lixo podem se encontrar expostos a situações adversas de trabalho, não só nos aspectos físicos exigidos pela atividade, como também nos aspectos psicossociais. Ao fazerem a manipulação do resíduo sólido, eles ficam expostos aos resíduos contaminados e à sobrecarga de trabalho, e o aspecto psicossocial, há falta de reconhecimento da população e dos empregadores. Esses aspectos refletem-se na autoestima que costuma ser baixa nessa categoria, contribuindo para as morbidades que afetam esses trabalhadores. (ILÁRIO, 1989; ROBAZZI et al., 1994; VELLOSO; SANTOS; ANJOS, 1997)

Estudos que focalizam as demandas do trabalho da coleta de lixo apontam o papel importante da exposição aos aerodispersóides, o que é compatível com o achado de queixas respiratórias entre os trabalhadores. Verifica-se excesso de risco para bronquites e outros problemas pulmonares, embora pouco se saiba sobre a causalidade desses problemas na relação com o trabalho na coleta de lixo. A literatura também aponta entre os trabalhadores da limpeza urbana, os acidentes de trabalho, muitas vezes, decorrentes do difícil acesso ao lixo, do seu mau acondicionamento ou do inadequado desenho ou condição de uso 
dos meios e equipamentos, em um contexto de excesso de trabalho. (KUIJER; SLUITER; FRIGS-DRESEN, 2010; PAULSEN et al., 1995)

Os trabalhadores de limpeza urbana desenvolvem suas atividades num território diversificado e complexo, a rua. Isto pressupõe que essa atividade coloca estes trabalhadores expostos a vários outros riscos que podem estar ou não diretamente relacionados às suas atividades ocupacionais, como por exemplo, atropelamentos, mordeduras de cães, violência urbana (assaltos, envolvimento em brigas, balas perdidas), condições precárias das vias públicas e inadequação de condição ou uso dos equipamentos de proteção individual, o que demonstra a complexidade dessa função. (OLIVEIRA, 2008)

A exposição dos trabalhadores a uma diversidade de agentes nocivos à saúde torna o trabalho na limpeza urbana um dos mais arriscados e insalubres.

A literatura ainda destaca os problemas cardiovasculares, perdas auditivas, tabagismo e alcoolismo como problemas de saúde de destaque nesse grupo ocupacional. (ROBAZZI et al., 1994; MIGLIORANSA et al., 2003)

As altas demandas biomecânicas também presentes na limpeza urbana são associadas aos problemas musculoesqueléticos, frequentes entre os coletores. Alguns autores chamam atenção para as tarefas que implicam puxar, empurrar, inclinar cargas, ou seja, excessiva manipulação de peso, na determinação dos problemas musculoesqueléticos nesse grupo ocupacional. (PATARO; FERNANDES, no prelo; KUIJER; SLUITER; FRIGS-DRESEN, 2010; PAULSEN et al., 1995)

Constatada a elevada prevalência de possíveis fatores de risco para DME na limpeza urbana, estudos que investiguem esses efeitos à saúde podem contribuir para a melhoria nas condições de trabalho neste setor de serviços, ao fornecerem subsídios para possíveis tomadas de decisões relativas às intervenções necessárias.

\section{Métodos}

Foi realizado um estudo de corte transversal com 657 trabalhadores de limpeza urbana de Salvador, Bahia. Optou-se pela realização de um censo com coletores, motoristas, agentes especiais e trabalhadores da manutenção. Foram incluídos no estudo todos os trabalhadores 
ativos. Aqueles que se encontravam afastados temporariamente do trabalho por licença médica foram contatados para participar da pesquisa, a fim de minimizar o efeito sobrevivência do trabalhador sadio.

Para a coleta de dados, foi aplicado um questionário aos trabalhadores, durante o expediente de trabalho, em local reservado, assegurando privacidade. Esse instrumento para a coleta de dados foi uma adaptação do questionário elaborado e utilizado por Fernandes (2004) para o estudo de DME em trabalhadores da indústria de plástico.

A equipe de entrevistadores, formada pelo autor principal, outro pesquisador e estudantes de graduação em fisioterapia e enfermagem, foi treinada previamente para o uso do instrumento, esclarecida acerca de cada item do questionário e das alternativas de resposta.

O questionário continha perguntas sobre aspectos sociodemográficos, história ocupacional no emprego atual e vida laboral pregressa, demandas físicas e psicossociais no trabalho, sobre presença de filhos, hábito de fumar, consumo de bebidas alcoólicas, uso de medicamentos e de tranquilizante, atividades domésticas, atividades físicas e esportivas e questões sobre DME. Foram realizadas medidas de peso e altura com o objetivo de calcular o índice de massa corporal.

Os dados sobre demanda física no trabalho foram obtidos por meio de questões respondidas pelos trabalhadores em escala de 0 a 5 pontos, com âncoras nas extremidades. As questões foram relativas as posturas de trabalho (gerais e de segmentos corporais), movimentos repetitivos, força muscular exercida, levantamento e manuseio de cargas.

Os aspectos psicossociais do trabalho (demanda psicológica, controle sobre o trabalho e suporte social) foram verificados com o uso do Job Content Questionnaire (JCQ). (KARASEK, 1985; ARAÚJO; KARASEK, 2008) Muito se tem usado o modelo demanda-controle de Karasek (1985), levando-se em consideração também o suporte social, nas pesquisas sobre DME. Neste estudo com trabalhadores de limpeza urbana foi evidenciada a necessidade de considerar simultaneamente as variáveis de demanda, controle e suporte. Para que isso fosse possível foi utilizado o critério proposto por Devereux, Buckle e Vlachonikolis (1999) que consideram alta exposição a esses estressores, a satisfação de pelo menos duas das seguintes condições: de alta demanda, baixo controle e baixo suporte. 
Dados sobre sintomas de DME foram coletados por meio da versão ampliada do Nordic Musculoskeletal Questionnaire (NMQ), instrumento amplamente utilizado em investigações epidemiológicas sobre DME, em todo o mundo. (KUORINKA; FORCIER, 1995) Avaliou-se a presença de dor ou desconforto nos últimos 12 meses nas áreas anatômicas estudadas e sua severidade, duração e frequência.

Foi definido como "caso de DME", dor em uma ou mais das seguintes áreas corporais: mão, punho, antebraço, cotovelo, pescoço, ombro ou parte alta do dorso, nos últimos doze meses, com duração de mais de uma semana ou frequência mínima mensal, não decorrente de trauma agudo, acompanhada de pelo menos um dos seguintes sinais de gravidade: grau de severidade maior ou igual a 3, em uma escala numérica de 0 a 5, com âncoras nas extremidades (nenhum desconforto a desconforto insuportável); busca de atenção médica pelo problema; ausência ao trabalho (oficial ou não); mudança de trabalho por restrição de saúde.

A prevalência de dor nos últimos doze meses, sem critério de duração, frequência e gravidade, foi descrita para permitir comparação com a literatura, já que boa parte dos estudos apenas registra dor nos últimos doze meses, sem especificá-la.

A população foi, em uma primeira etapa, descrita de acordo com as variáveis sociodemográficas, de hábitos de vida e ocupacionais, todas de interesse para o estudo dos DME: idade, estado civil, escolaridade, presença de filhos menores de dois anos de idade, tempo de trabalho (incluindo vínculos formais e informais), regime de trabalho, horas-extras, demandas físicas no trabalho, demandas psicossociais no trabalho, atividade física ou esportiva, trabalho doméstico, sobrepeso, obesidade, tabagismo, uso de bebida alcoólica. Essas variáveis foram utilizadas na etapa seguinte de análise, na qual foram investigados os possíveis fatores associados aos DME em pescoço ou ombro ou parte alta do dorso (DMEP).

Todas as variáveis foram dicotomizadas. A presença de sobrepeso ou obesidade foi considerada com índice de massa corporal (IMC) $>25$ $\mathrm{Kg} / \mathrm{m}^{2}$; estado civil foi estratificado em casados ou que "viviam juntos" e não casados, que incluíam solteiros, viúvos e divorciados; para o uso de bebida alcoólica, o consumo com frequência de uma vez ou mais na semana foi adotado como ponto de corte. As demais variáveis foram 
utilizadas tendo a mediana como ponto de corte. Tabagismo não foi incluído na análise multivariada, devido à sua baixa prevalência na população estudada.

$\mathrm{Na}$ abordagem estatística dos dados, foram obtidos a prevalência de DME nos diversos segmentos dos membros superiores, pescoço e parte alta do dorso, as médias e seus respectivos desvios-padrão ou a mediana, para algumas variáveis independentes, e o percentual de exposição para as demais variáveis. Descreveram-se também as demandas físicas no trabalho, utilizando-se sua distribuição de acordo com os quartis. Utilizou-se na etapa descritiva e na análise tabular o programa Epi-Info 6.04.

Considerando-se a magnitude de trabalhadores cuja ocupação era a de coletor, e conhecidas às características peculiares desta ocupação já descritas em literatura por Camada, Pataro e Fernandes (2012), optou-se por apresentar os resultados da etapa descritiva para coletores e não coletores (estes agrupando motoristas, agentes especiais e pessoal de manutenção).

Para a identificação dos fatores associados aos DME em pescoço ou ombro ou parte alta do dorso, realizou-se a análise de regressão logística não condicional, utilizando-se o programa estatístico R. A pré-seleção das variáveis independentes foi baseada na plausibilidade biológica das associações.

Considerando tratar-se de um censo, e sabendo que os métodos da inferência estatística se aplicam apenas para análise de resultados obtidos a partir de uma amostra aleatória, os resultados descritivos não apresentam testes estatísticos e os resultados finais da modelagem na regressão logística foram apresentados apenas através da medida de associação, sem incluir intervalos de confiança. (STRASAK et al., 2007; SILVANY NETO, 2008; CONCEIÇÃO, 2008)

Como o resultado final da regressão logística fornece a odds ratio como medida de associação, esta foi convertida para razão de prevalência, com o cálculo de seus respectivos intervalos de confiança pelo método Delta. (OLIVEIRA; SANTANA; LOPES, 1997)

Este projeto de pesquisa foi aprovado pelo Comitê de Ética em Pesquisa do Hospital São Rafael com o número do processo no 48/09.

Todos os trabalhadores pesquisados foram informados sobre os objetivos da pesquisa, sobre a instituição responsável por esta, e de 
que a empresa apenas liberou o acesso dos pesquisadores à empresa, não tendo qualquer participação na realização da pesquisa. Os trabalhadores que aceitaram participar do estudo assinaram um Termo de Consentimento Livre e Esclarecido e foram assegurados do sigilo das informações, da participação voluntária e do anonimato.

\section{Resultados}

Dos 657 trabalhadores inseridos na limpeza urbana, foram estudados 624 , todos do sexo masculino. O percentual de perdas e recusas foi de $5 \%$.

A média da idade dos entrevistados foi de 33 anos, variando de 19 a 74 anos, no entanto apenas 26 indivíduos tinham mais de 50 anos. Apenas $37 \%$ possuíam o ensino médio completo. Setenta e dois por cento dos trabalhadores eram casados, ou viviam junto com um parceiro estável, e $18 \%$ possuíam filhos menores de dois anos. Foi constatado o hábito de fumar em $15 \%$ dos trabalhadores e o consumo de bebidas alcoólicas com frequência de uma vez por semana ou mais foi referido por $57 \%$ da população estudada (dados não mostrados em tabela neste trabalho).

Dos trabalhadores, $59 \%$ eram coletores e $41 \%$, não coletores. Eram 367 coletores, 118 motoristas, 84 agentes especiais de limpeza e 55 trabalhadores de manutenção (civil, elétrica e mecânica). Os coletores apresentaram em menor proporção o IMC elevado (sobrepeso ou obesidade), 30\%, do que os não coletores (61\%). Quanto às demandas físicas no trabalho, a postura anômala de tronco se fez presente para $78 \%$ dos coletores e $29 \%$ dos não coletores (Figura 1). Os coletores estavam muito mais envolvidos em trabalhos dinâmicos (83\%) que os não coletores $(26 \%)$ e exerciam maior esforço físico, tal como levantamento de carga. Durante sua jornada de trabalho, a maioria dos coletores trabalhava com os braços elevados (79\%), enquanto uma menor proporção dos não coletores mantinha essa posição (39\%). Os coletores estavam mais expostos às elevadas demandas psicossociais do trabalho (55\%) que os não coletores (44\%) e seu trabalho envolvia maior proporção de horas extras que os não coletores ( $94 \%$ e $73 \%$, respectivamente), apesar da alta proporção desta jornada extra para todos (Tabela 1). 
Tabela 1 - Características sociodemográficas, ocupacionais e hábitos de vida de Coletores e não Coletores da Limpeza Urbana. Salvador, 2010 (N=624).

\begin{tabular}{l|c|c}
\multicolumn{1}{c|}{ Características } & Coletores & $\begin{array}{c}\text { Não } \\
\text { Coletores } \\
\end{array}$ \\
\hline População & 59 & 41 \\
\hline Estado civil (casado ou vive junto) & 70 & 75 \\
\hline Uso de bebida pelo menos uma vez na semana & 58 & 57 \\
\hline Faz alguma atividade física de lazer & 45 & 53 \\
\hline Tem filhos menores que dois anos & 20 & 15 \\
\hline IMC (sobrepeso ou obesidade) & 30 & 61 \\
\hline Faz horas extras & 94 & 73 \\
\hline Vibração de corpo inteiro & 66 & 55 \\
\hline Postura anômala de tronco & 78 & 29 \\
\hline Trabalho dinâmico & 83 & 12 \\
\hline Esforço físico (manuseio de carga) & 77 & 26 \\
\hline Trabalho agachado & 81 & 28 \\
\hline Braços elevados & 79 & 39 \\
\hline Alta demanda psicossocial & 55 & 44 \\
\hline
\end{tabular}

Fonte: (PEREIRA; FERNANDES, 2010) 
Figura 1 - A exigência de posturas anômalas de tronco na realização do trabalho de Coletores

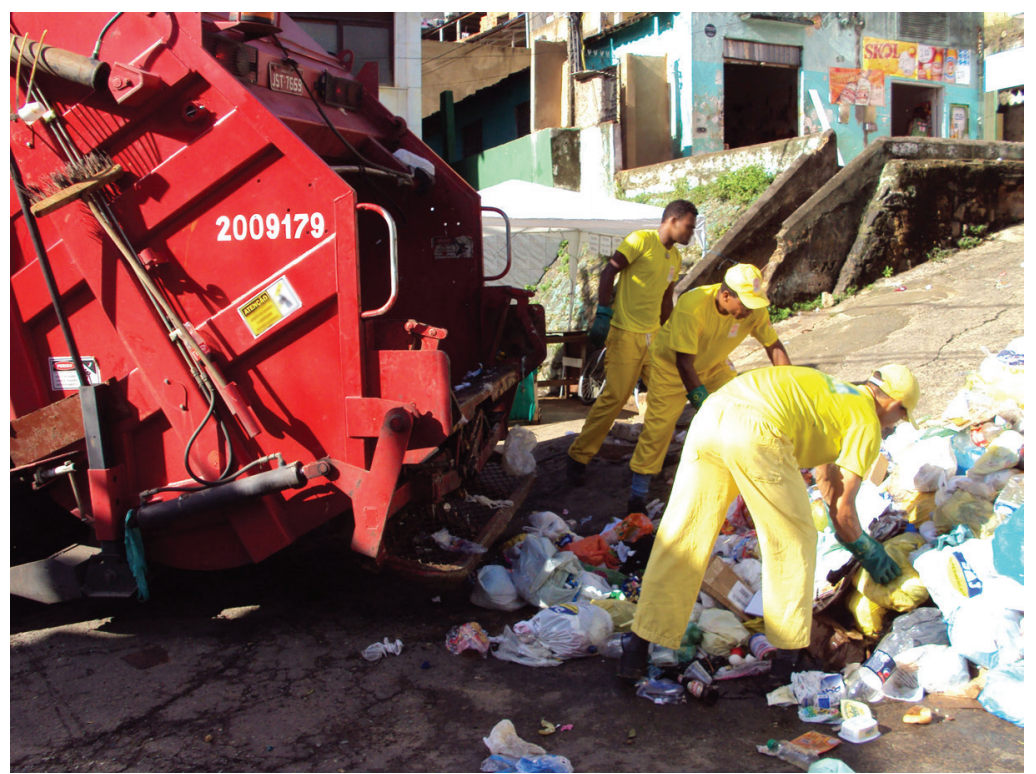

Fonte: (PEREIRA; FERNANDES, 2010)

Na tabela 2 é mostrada a distribuição da exposição para 12 variáveis de demandas físicas, avaliadas por meio de escalas de 6 pontos (0 a 5), com âncoras nas extremidades. Descreveu-se na tabela o ponto da escala de resposta (0 a 5) nos $1^{\circ}(\mathrm{Q} 1), 2^{\circ}(\mathrm{Q} 2)$ e $3^{\circ}(\mathrm{Q} 3)$ quartis. A distribuição é apresentada para toda a população, para coletores e não coletores nos três diferentes quartis. Observa-se, quanto às posturas gerais de trabalho, que quase todo o trabalho é realizado na postura em pé ou andando para coletores (Figura 2). Para o trabalho sentado, o ponto 0 na escala, jamais sentado, se mantém até pelo menos o terceiro quartil para esses trabalhadores. Apenas entre os não coletores registra-se o trabalho sentado (pontos $>0$ ), para os quais o ponto $2 \mathrm{da}$ escala é atingido no segundo quartil. O trabalho dos coletores é muito dinâmico, implicando a postura de trabalho andando, correndo e saltando de diferentes níveis. Para eles, o tempo todo (ponto 5 da escala) o trabalho é feito andando (ponto 5 já no $1^{\circ}$ quartil), ao passo que para os não coletores o ponto 2 da escala é atingido no segundo quartil. As atividades com levantamento de carga são referidas como mais frequentes pelos coletores e chegam a ocupar quase toda a jornada. $\mathrm{Na}$ Tabela 2, é possível observar os dados que caracterizam a exposição 
para toda a população, mas a distribuição por grupo de ocupação indica a existência de tarefas e demandas bastante diferentes para coletores e não coletores. As posturas inadequadas como: agachado, tronco inclinado para frente ou rodado e braços elevados acima da altura dos ombros, eram comuns no dia a dia, particularmente entre os coletores.

Tabela 2 - Demandas físicas no trabalho, distribuídas por quartis (Q), para trabalhadores da Limpeza Urbana. Salvador, 2010.

\begin{tabular}{|c|c|c|c|c|c|c|c|c|c|}
\hline \multirow{2}{*}{$\begin{array}{l}\text { Demanda Física } \\
\begin{array}{c}0=\text { jamais } 5=0 \\
\text { tempo todo }\end{array}\end{array}$} & \multicolumn{3}{|c|}{ População Total } & \multicolumn{3}{|c|}{ Coletor } & \multicolumn{3}{|c|}{ Não Coletor } \\
\hline & $1^{\circ} \mathrm{Q}$ & $2^{\circ} \mathrm{Q}$ & $3^{\circ} \mathrm{Q}$ & $1^{\circ} \mathrm{Q}$ & $2^{\circ} \mathrm{Q}$ & $3^{\circ} \mathrm{Q}$ & $1^{\circ} \mathrm{Q}$ & $2^{\circ} \mathrm{Q}$ & $3^{\circ} \mathrm{Q}$ \\
\hline Trabalho sentado & 0 & 0 & 2 & 0 & 0 & 0 & 0 & 2 & 5 \\
\hline Trabalho em pé & 3 & 5 & 5 & 5 & 5 & 5 & 0 & 3 & 5 \\
\hline Trabalho andando & 1 & 3 & 5 & 5 & 5 & 5 & 0 & 2 & 5 \\
\hline Correndo & 0 & 4 & 5 & 5 & 5 & 5 & 0 & 0 & 0 \\
\hline $\begin{array}{l}\text { Saltando de níveis dife- } \\
\text { rentes }\end{array}$ & 2 & 4 & 5 & 4 & 5 & 5 & 0 & 2 & 3 \\
\hline Trabalho agachado & 1 & 3 & 5 & 3 & 4 & 5 & 0 & 1 & 3 \\
\hline $\begin{array}{l}\text { Tronco inclinado para } \\
\text { frente }\end{array}$ & 2 & 4 & 5 & 3 & 5 & 5 & 1 & 3 & 4 \\
\hline Tronco rodado & 2 & 4 & 5 & 3 & 5 & 5 & 1 & 3 & 4 \\
\hline $\begin{array}{l}\text { Braços acima da altura } \\
\text { dos ombros }\end{array}$ & 1 & 3 & 5 & 3 & 5 & 5 & 0 & 2 & 3 \\
\hline Levantando carga & 2 & 4 & 5 & 4 & 5 & 5 & 0 & 1 & 4 \\
\hline Empurrando carga & 1 & 4 & 5 & 3 & 4 & 5 & 0 & 1 & 3 \\
\hline Puxando carga & 1 & 3 & 5 & 3 & 4 & 5 & 0 & 0 & 4 \\
\hline
\end{tabular}

Fonte: (PEREIRA; FERNANDES, 2010) 
Figura 2 - O trabalho de Coletores, em pé ou andando durante quase toda a jornada.

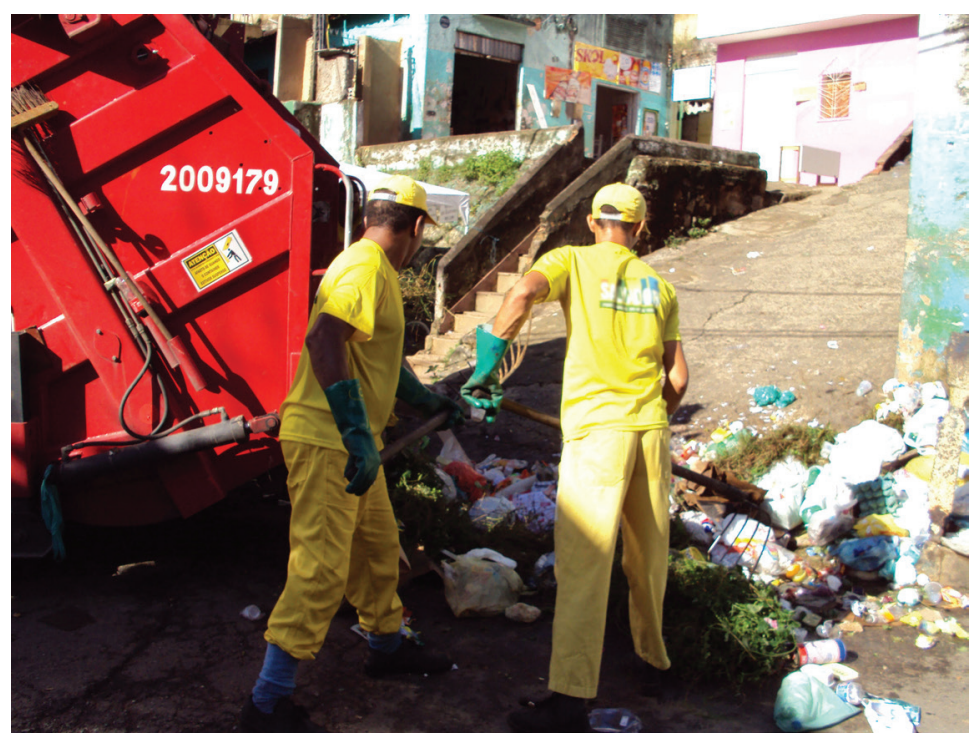

Fonte: (PEREIRA; FERNANDES, 2010)

Quanto à queixa de dor musculoesquelética, que se referia há pelo menos um episódio de dor em qualquer segmento dos membros superiores, pescoço e parte alta do dorso nos últimos doze meses, verificou-se uma prevalência nesta população de trabalhadores de limpeza urbana de $52 \%$. Os coletores referiram maior prevalência de dor em pescoço ou ombro ou parte alta do dorso $(41 \%)$ que os não coletores $(33 \%)$, no entanto, para a região distal dos membros superiores (MMSS) não houve diferença marcante (Tabela 3). 
TABELA 3 - Prevalência de dor nos últimos doze meses, segundo segmento de membros superiores, pescoço e parte alta do dorso em trabalhadores da Limpeza Urbana. Salvador, 2010. $(\mathrm{N}=624)$

\begin{tabular}{l|c|c|c}
\multicolumn{1}{c|}{ Segmento corporal referido } & $\begin{array}{c}\text { População } \\
\text { Total }\end{array}$ & $\begin{array}{c}\text { Coletor } \\
\%\end{array}$ & $\begin{array}{c}\text { Não } \\
\text { coletor }\end{array}$ \\
\hline $\begin{array}{l}\text { Em alguma região dos membros superiores ou pescoço } \\
\text { ou parte alta do dorso }\end{array}$ & 52 & 54 & 49 \\
\hline Pescoço ou ombro ou parte alta do dorso & 38 & 41 & 33 \\
\hline Cotovelo ou antebraço ou punho ou mão & 27 & 28 & 26 \\
\hline Pescoço & 16 & 14 & 18 \\
\hline Ombro & 24 & 29 & 18 \\
\hline Cotovelo ou antebraço & 10 & 10 & 10 \\
\hline Punho ou mão & 21 & 23 & 18 \\
\hline Parte alta do dorso & 14 & 15 & 13 \\
\hline
\end{tabular}

Fonte: (PEREIRA; FERNANDES, 2010)

Quanto à prevalência de dor, com duração de mais de uma semana ou frequência mínima mensal, com algum outro sinal de gravidade, conforme já descrito, em pelo menos um dos segmentos dos membros superiores, pescoço ou parte alta do dorso, esta foi de $39 \%$ para a população inteira. Constatou-se a mais elevada prevalência para dor em ombros, com $18 \%$, quando se descreveu cada segmento separadamente. A prevalência de dor em pelo menos um dos segmentos da região referida foi mais elevada nos coletores $(42,0 \%)$, do que nos não coletores (35\%) (Tabela 4). 
Tabela 4 - Prevalência de Distúrbios Musculoesqueléticos ${ }^{1}$, segundo segmento de membros superiores, pescoço e parte alta do dorso, em trabalhadores da Limpeza Urbana. Salvador, 2010. $(\mathrm{N}=624)$

\begin{tabular}{l|c|c|c}
\multicolumn{1}{c|}{ Segmento corporal referido } & $\begin{array}{c}\text { População } \\
\text { Total }\end{array}$ & $\begin{array}{c}\text { Coletor } \\
\%\end{array}$ & $\begin{array}{c}\text { Não } \\
\text { coletor } \\
\%\end{array}$ \\
\hline $\begin{array}{l}\text { Em alguma região dos membros superiores ou pescoço } \\
\text { ou parte alta do dorso }\end{array}$ & 39 & 42 & 35 \\
\hline Pescoço ou ombro ou parte alta do dorso & 28 & 31 & 24 \\
\hline $\begin{array}{l}\text { Extremidades superiores distais (cotovelo ou antebraço } \\
\text { ou punho ou mão) }\end{array}$ & 20 & 23 & 17 \\
\hline Pescoço & 11 & 10 & 12 \\
\hline Ombro & 18 & 21 & 13 \\
\hline Cotovelo ou antebraço & 7 & 8 & 6 \\
\hline Punho ou mão & 15 & 18 & 12 \\
\hline Parte alta do dorso & 11 & 12 & 10 \\
\hline
\end{tabular}

${ }^{1}$ Dor nos últimos doze meses, com duração de mais de uma semana ou frequência mínima mensal, não decorrente de trauma agudo, acompanhada de pelo menos um dos seguintes sinais de gravidade: grau de severidade maior ou igual a 3, busca de atenção médica pelo problema, ausência ao trabalho, mudança de trabalho.

Fonte: (PEREIRA; FERNANDES, 2010)

Por meio da análise multivariada verificou-se que DME em pescoço ou ombro ou parte alta do dorso (DMEP) foi 1,25 vezes mais frequente entre expostos à postura de braços acima dos ombros. A exposição às elevadas demandas psicossociais $(\mathrm{RP}=1,32)$ e o tempo de trabalho na empresa maior que 56 meses $(\mathrm{RP}=1,28)$ associaram-se com DMEP. Beber uma vez ou mais na semana $(\mathrm{RP}=0,68)$ e ter filhos menores de dois anos $(\mathrm{RP}=0,63)$ estavam associados à DMEP, de forma inversa (Tabela 5). 
Tabela 5 - Distúrbios Musculoesqueléticos em pescoço, ombro ou parte alta do dorso e fatores associados, em trabalhadores da Limpeza Urbana. Salvador, 2010.

\begin{tabular}{l|c|c}
\multicolumn{1}{c|}{ Variáveis associadas } & RP bruta & RP ajustada \\
\hline Beber uma ou mais vezes por semana & 0,79 & 0,68 \\
\hline Ter filhos < que dois anos & 0,64 & 0,63 \\
\hline Postura de trabalho com braços acima dos ombros & 1,30 & 1,25 \\
\hline Demandas psicossociais & 1,34 & 1,32 \\
\hline Tempo de trabalho > 56 meses & 1,33 & 1,28 \\
\hline
\end{tabular}

Fonte: (PEREIRA; FERNANDES, 2010)

\section{Discussão}

A prevalência de dor em geral e de dor com duração ou frequência e gravidade especificadas em alguma região dos membros superiores, pescoço ou parte alta do dorso de trabalhadores de limpeza urbana em Salvador, foi elevada. Essa prevalência foi superior às relatadas por outros estudos com trabalhadores do setor de serviço e indústria. (GRAÇA; ARAÚJO; SILVA, 2006; PICOLOTO; SILVEIRA, 2008; CARDOSO et al., 2009; FERNANDES; CARVALHO; ASSUNÇÃO, 2011) Deve-se ressaltar que os estudos citados, embora tenham utilizado o NMQ como instrumento para coleta de dados de dor musculoesquelética, não utilizaram os critérios de gravidade que foram utilizados neste estudo, para definição de "caso de DME", com exceção de Fernandes, Carvalho e Assunção (2011).

O critério utilizado neste estudo para definição de caso considera: se há ou não dor nos últimos doze meses, incorpora a duração de mais de uma semana ou a frequência de pelo menos uma vez por mês, levando à busca de atenção médica ou mudança de trabalho; ou se apresenta grau de severidade maior ou igual a 3 (em 0 a 5). Esta dor em trabalhadores que se encontravam em plena atividade de trabalho representa importante morbidade nesta população, tendo em vista, a possibilidade de evolução para quadros incapacitantes, uma vez que os trabalhadores continuam na mesma atividade de trabalho que pode estar relacionada com a dor. O uso deste critério para definição de caso visou aumentar a especificidade da queixa, permitindo apontar com uma 
maior propriedade, a dimensão e relevância dos DME nessa população de trabalhadores de limpeza urbana.

Realizou-se descrição conjunta de ombro, pescoço e parte alta do dorso porque esses segmentos corporais atuam como uma unidade funcional, ou seja, é difícil identificar especificamente o local de origem do sintoma referido. (NATIONAL RESEARCH COUNCIL; INSTITUTE OF MEDICINE, 2001) Portanto, dor referida em ombro pode ter origem em pescoço e vice-versa, além do envolvimento da parte superior do dorso que pode ser referido em um desses outros locais. No entanto, para fins de comparação com outros estudos, descreveram-se também as prevalências para pescoço e ombro, separadamente.

Picoloto e Silveira (2008) relataram prevalência de $18 \%$ para os sintomas nos punhos, em metalúrgicos, enquanto Mehrad e colaboradores (2008), em estudo no Irã, constataram que 7,5\% dos coletores referiam dor nos punhos ou mãos. Neste estudo, entre coletores, foi encontrada a prevalência de $23 \%$ para sintomas de dor nos punhos ou mãos. No mesmo estudo de Mehrad et al. (2008), foi encontrada prevalência de dor nos ombros de $18 \%$, enquanto no presente estudo, entre os coletores, foi encontrada prevalência de $29 \%$ de dor neste segmento. Portanto, a magnitude de queixa entre os coletores é relevante e superior ao encontrado, inclusive, em trabalhadores da mesma categoria em outro país.

Considerando os casos mais específicos, ou seja, aqueles com duração, frequência e gravidade de dor estabelecidas, a prevalência de DME para alguma região de MMSS ou pescoço ou parte alta do dorso (DMEP) em coletores foi de $42,0 \%$ e para as regiões do ombro e pescoço, separadamente, $21 \%$ e $10 \%$, respectivamente. Fernandes e colaboradores (2010), em estudo com os trabalhadores da indústria de plásticos da Região Metropolitana de Salvador, encontraram prevalência de DME em alguma região de MMSS ou pescoço ou parte alta do dorso de $31 \%$, enquanto para a região do ombro, $11 \%$ e pescoço, $7 \%$.

O ombro apresentou-se como sendo a principal região dos MMSS acometida nos coletores. Além disso, verificou-se que a prevalência de sintomas em pescoço, ombro ou parte alta do dorso, tomadas conjuntamente, foi mais alta (31\%) do que a prevalência em extremidades distais de MMSS (antebraço ou punho ou mão), de 23\%, com a principal contribuição dada por dor em punho ou mão, que corresponde 
a 18\%. Fernandes, Carvalho e Assunção (2011) também encontraram maior prevalência em pescoço, ombro ou parte alta do dorso $(20,6 \%)$ do que em extremidades distais $(18,7 \%)$, mas esta diferença foi pouco relevante. Portanto, neste estudo, verificou-se maior magnitude de DME em membros superiores comparada à encontrada por FernandesCarvalho e Assunção (2011) em trabalhadores, das áreas de operação e manutenção da indústria de plásticos. Considerando que os trabalhadores industriários estudados por Fernandes, Carvalho e Assunção (2011) realizavam atividades com marcada demanda física para o corpo, pela exigência de esforço e manuseio de carga, os resultados da morbidade entre os trabalhadores de limpeza urbana e, em especial, entre os coletores podem ser reveladores das demandas intensas postas a esses trabalhadores na jornada diária.

Neste sentido, os achados sobre as demandas físicas no trabalho da Limpeza Urbana são relevantes e evidenciam uma alta carga de trabalho físico. Os coletores exercem tarefas com alta exigência sobre o corpo, como andar, correr e saltar de diferentes níveis durante a coleta do lixo. Por outro lado, o manuseio de carga está presente durante toda a jornada. Entre os motoristas, o trabalho sentado é mais presente. Em estudo ergonômico realizado com uma amostra da mesma população do presente estudo, Camada, Pataro e Fernandes (2012) verificaram que durante o manuseio de contêineres ou tonéis, os coletores realizam constantes movimentos de empurrar, puxar e levantar cargas pesadas. Afirmam as autoras que a intensa demanda física sob ritmo de trabalho acelerado contribui para o comprometimento da saúde e, em particular, para a ocorrência de sintomas musculoesqueléticos.

A partir da análise multivariada, este estudo apresentou também resultados que mostram a contribuição das demandas físicas e psicossociais no trabalho para o desenvolvimento de DME em pescoço, ombro e parte alta do dorso (DMEP), que se associaram positivamente com essas demandas.

Fonseca e Fernandes (2010), em estudo com técnicos e auxiliares de enfermagem, encontraram associação positiva entre DMEP e demandas físicas no trabalho, particularmente manuseio de carga. No presente estudo, foi encontrada associação entre DMEP e postura de trabalho com braços acima dos ombros. 
Alguns estudos têm apresentado associação entre DME em regiões centrais como pescoço, ombros, ou parte alta do dorso e demanda psicossocial; já em regiões periféricas as demandas físicas do trabalho têm sido observadas como o principal preditor. (TOOMINGAS et al.; 1997, PINHEIRO; TRÓCCOLI; PAZ, 2006) Neste estudo, os mais expostos a demandas psicossociais (incorporando as dimensões de demanda psicológica, controle no trabalho e suporte social) também apresentam maior prevalência de DMEP. Esta associação também foi verificada por Fonseca e Fernandes (2010) entre os técnicos e auxiliares de enfermagem, por Fernandes e colaboradores (2010) entre os trabalhadores da indústria de plástico e por Andersen, Haahr e Frost (2007) em uma coorte de trabalhadores do setor de serviços.

O ritmo acelerado é, entre as demandas psicossociais, o fator de risco mais citado na literatura, especialmente associado aos DME em extremidades superiores. Camada, Pataro e Fernandes (2012) constataram que, a fim de atender às exigências da gestão e atingir as metas de produção do serviço, os coletores realizam suas atividades em ritmo acelerado. Assim, os resultados esperados pela gestão somente são atingidos à custa de hipersolicitação física e psíquica dos trabalhadores. As autoras discutem, além disso, que um período de descanso insuficiente é fator de desgaste físico e pode precipitar distúrbios musculoesqueléticos.

Mas, além da alta demanda psicológica (que incorpora o ritmo acelerado) e do baixo controle, alguns estudos referem o baixo suporte social como fator associado aos DME em pescoço e ombros. (AHLBERG-HULTEN; THEORELL; SIGALA, 1995; SMITH et al., 2004)

O maior tempo de trabalho na empresa apresentou associação com a maior prevalência de DMEP. Assim como nesta pesquisa, o estudo realizado por Fonseca e Fernandes (2010) encontrou associação entre tempo de trabalho e DMEP. A força da associação encontrada neste estudo foi inferior ao encontrado por Fonseca e Fernandes (2010), mas o tempo de trabalho associado ao maior adoecimento foi maior que 19 anos (>228 meses) para trabalhadoras de enfermagem. Portanto, os trabalhadores da limpeza urbana já apresentam DMEP em um tempo mais curto de trabalho, o que pode indicar a natureza mais penosa daquela atividade. 
Há estudos que apontam que as atividades ligadas ao cuidado de casa ou de filhos podem contribuir para o surgimento de DME, principalmente em mulheres. (STRAZDINS; BAMMER, 2004) Neste estudo, a associação entre DMEP e ter filhos menores de dois anos foi negativa, ou seja, esta variável representou possível fator de proteção. A literatura atribui os cuidados com os filhos pequenos uma sobrecarga para os membros superiores que poderia então representar fator de risco para dor nesta região. (FERNANDES, 2004; PINHEIRO; TRÓCCOLI; PAZ, 2006) Entretanto, o achado do presente estudo remete para a possibilidade de ter filhos constituir um estado emocional que protegeria para a percepção ou registro da dor entre esses pais. Além disso, não se pode afastar uma questão de gênero, já que a população estudada é composta por homens e esses podem não estar se responsabilizando habitualmente pelo cuidado com os filhos. Com mulheres, mães trabalhadoras, os resultados poderiam ser diferentes. Esta discussão, ainda preliminar, carece de novos estudos.

O uso de bebida apresentou associação negativa com DMEP. Segundo Mabuchi e colaboradores (2007), este uso poderia se constituir em uma forma de fuga para diminuir os efeitos da sobrecarga de trabalho e o sofrimento psíquico, porque ao proporcionar distensionamento de situações desconfortáveis geradas pelo estresse poderia reduzir a percepção ou o registro da dor. Além disso, a redução do estresse poderia ter efeito direto sobre a própria musculatura, distensionando-a. (PINHEIRO; TRÓCCOLI: PAZ, 2006)

\section{Considerações finais}

A elevada prevalência de DME em membros superiores encontrada entre os trabalhadores estudados, bem como as demandas físicas e psicossociais às quais estão expostos, apontam para a necessidade de atenção para essa categoria profissional e suas condições de trabalho.

Os achados sobre as demandas físicas no trabalho da Limpeza Urbana são relevantes e evidenciam uma alta carga de trabalho físico. Entre as ocupações, as tarefas exercidas principalmente pelos coletores são de alta exigência sobre o corpo, implicando manuseio de carga durante toda a jornada de trabalho. 
A intensa demanda física sob ritmo de trabalho acelerado contribui para a ocorrência de sintomas musculoesqueléticos, como se constatou neste estudo em que os mais expostos a demandas psicossociais (incorporando as dimensões de demanda psicológica, controle no trabalho e suporte social) apresentaram maior prevalência de DMEP.

Além disso, o achado de curto tempo de inserção na Limpeza Urbana com alta prevalência de DME, haja vista a média de tempo de trabalho de apenas 56 meses, pode indicar a natureza mais penosa desta atividade.

Faz-se necessária a aplicação do conhecimento já produzido para a melhoria das condições de trabalho desses trabalhadores. Porém, são bem vindos novos estudos, principalmente os de caráter analítico, para indicar novos caminhos a serem seguidos para a adoção de medidas preventivas.

\section{Referências}

AHLBERG-HULTEN, G. K.; THEORELL T.; SIGALA F. Social support, job strain and musculoskeletal pain among female health care personnel. Scandinavian Journal of Work, Environment \& Health, v. 21, n 6, p. 435-39, 1995.

ANDERSEN, J. H.; HAAHR, J. P.; FROST, P. Risk factors for more severe regional musculoskeletal symptoms: A two-year prospective study of a general working population. Arthritis \& Rheumatism, v. 56, n. 4, p. 1355-1364, 2007.

ARAÚJO, A. J. S. Paradoxos da Modernização: terceirização e segurança dos trabalhadores em uma refinaria de petróleo. Tese (Doutorado em Saúde Pública), 2001. Escola Nacional de Saúde Pública, Fundação Oswaldo Cruz, Rio de Janeiro, 2001.

ARAÚJO, T. M.; KARASEK, R. Validity and reliability of the job content questionnaire in formal and informal jobs in Brazil. Scandinavian Journal of Work Environment Health Suppl, v. 2, n. 6, p. 52-59, 2008.

BAHIA. Prefeitura Municipal de Salvador, Secretaria de Serviços Públicos e Prevenção à Violência. Plano Básico de Limpeza Urbana e Manejo de Resíduos Sólidos de Salvador, Salvador-Ba. , 2012. Disponível em: <www.limpurb.salvador.pub.gov.ba.br/>. Acesso em: 02 jul. 2012. 
BRANDÃO, A. G.; HORTA B. L.; TOMASI E. Sintomas

de Distúrbios osteomusculares em bancários de Pelotas e região: prevalência e fatores associados. Revista Brasileira de Epidemiologia, v. 8, n. 3, p. 295-305, 2005.

BRASIL. MINISTÉRIO DE PREVIDÊNCIA E ASSISTÊNCIA SOCIAL (MPAS). Anuário Estatístico da Previdência Social 2010. Disponível em: <http://www.mpas.gov.br> Acesso em: 12 dez. 2010.

CAMADA, I. M. O.; PATARO, S. M. S.; FERNANDES, R. C. P. Heavy physical work under time pressure: the garbage collection service- a case study. Work, v. 41, p. 462-469, 2012.

CARDOSO, J. P. et al. Prevalência de dor musculoesquelética em professores. Revista Brasileira de Epidemiologia, v. 12, n. 4, p. 604-14, 2009.

CESAT - Centro Estadual de Referência em Saúde do Trabalhador. Perfil Epidemiológico da Saúde do Trabalhador Síntese-Bahia. Bahia, 2009. CONCEIÇÃO, M. J. Leitura Crítica dos Dados Estatísticos em Trabalhos Científicos. Rev. Bras. Anestesiol, n. 58, p. 260-266, 2008.

COSTA, B. R.; VIEIRA, E. R. Risk factors for work-related musculoskeletal disorders: a systematic review of recent longitudinal studies. American Journal of Industrial Medicine, v. 53, n. 3, p. 285-323, 2009.

DEVEREUX, J. J. , BUCKLE, P. W. , VLACHONIKOLIS, I. Interactions between physicaland psychosocial risk factors at work increase the risk of back disorders: an epidemiological approach.

Occupational Environmental Medicine, v. 56, p. 343-353, 1999.

DRUCK, G. Trabalho precarização e resistências: novos e velhos desafios? In: DRUCK, G.; FRANCO, T (Org. ). Trabalho, precarização e resistências. Caderno CRH, Salvador, Universidade Federal da Bahia, v. 24, n. 1, p. 35-55, 2011.

FERNANDES, R. C. P. Distúrbios Musculoesqueléticos e trabalho industrial. 2004, 287f. Tese (Doutorado em saúde pública) - Instituto de Saúde Coletiva, Universidade Federal da Bahia, Salvador, 2004.

FERNANDES, R. C. P. et al. Muskuloskeletal disorders among workers in plastic manufacturing plants. Revista Brasileira de Epidemiologia, n. 13, p. 11-10, 2010.

FERNANDES, R. C. P.; CARVALHO, F. M.; ASSUNÇÃO, A. A. Prevalence of musculoskeletal disorders among plastics industry workers. Cadernos de Saúde Pública, v. 27, n. 1, p. 78-86, 2011. 
FONSECA, N. R.; FERNANDES, R. C. P. Fatores associados aos distúrbios musculoesqueléticos em trabalhadores de enfermagem. Revista LatinoAmericana de Enfermagem, v. 18, n. 6, p. 1076-1083, nov. /dez. 2010.

GRAÇA, C. C.; ARAÚJO, T. M.; SILVA, C. E. P. Prevalência de dor muscoloesquelética em cirurgiões-dentistas. Revista Brasileira de Saúde Pública, v. 30, n. 1, p. 59-76, jan. /jun. 2006.

ILÁRIO, E. Estudo de morbidade em coletores de lixo de um grande centro urbano. Revista Brasileira de Saúde Ocupacional, v. 17, n. 66, p. 7-12, 1989.

KALIMO, R. Psychosocial factors and worker's health: an overview. Word Health Organization, 1987.

KARASEK, R. Job Content Instrument: Questionnaire and User's guide. Massachusetts: University of Massachusetts. Amherst, 1985.

KUIJER, P. P. F. M.; SLUITER, J. K.; FRINGS-DRESEN, M. H. W. Health and Safety in Waste Collection: Towards EvidenceBased Worker Health Surveillance. American Journal of Industrial Medicine, v. 53, p. 1040-1064, 2010.

KUORINKA, I.; FORCIER, L. Work related musculoskeletal disorders (WMSDs): a reference book for prevention. London: Taylor \& Francis, 1995.

MABUCHI, A. S. et al. Uso de bebidas alcoólicas. Revista LatinoAmericana de Enfermagem, v. 15, n. 3, maio-jun., 2007.

MAGNAGO, T. S. B. S. et al. Distúrbios músculoesqueléticos em trabalhadores de enfermagem: associação com condições de trabalho. Revista Brasileira de Enfermagem, v. 60, n. 6, p. 701-705, 2010.

MARRAS, W. S. et al. National occupational researchagenda (NORA) future directions in occupational musculoskeletal disorder health research. Applied Ergonomics, v. 40, p. 15-22, 2009.

MEHRDAD, R. et al. Musculoskeletal disorders among municipal solid wast workers. Acta Medica Iranica, v. 46, n. 3, 2008.

MIGLIORANSA, M. H. et al. Estudo epidemiológico dos coletores de lixo seletivo. Revista Brasileira de Saúde Ocupacional, v. 28, n. 107/108, p. 19-28, 2003.

NATIONAL RESEARCH COUNCIL - NRC; INSTITUTE OF MEDICINE - IM Musculoskeletal disorders and the workplace: low back and upper extremities. Panel on musculoskeletal disorders and the workplace. Commission on behavioral and social sciences and education. Washington, DC: National Academy Press, 2001. 
OLIVEIRA, M. G. Características organizacionais e acidentes ocupacionais em empresas de limpeza urbana de Salvador-

Ba. 2008. Tese (Doutorado em saúde pública). Instituto de Saúde Coletiva - Universidade Federal da Bahia, Salvador, 2008.

OLIVEIRA, N. F.; SANTANA, V. S.; LOPES, A. A. Razões de prevalência e uso do método delta para intervalos de confiança em regressão logística. Revista Saúde Pública, v. 31, p. 90-99, 1997.

PATARO, S. M. S.; FERNANDES, R. C. P. Trabalho físico pesado e dor lombar: a realidade na limpeza urbana. Revista Brasileira de Epidemiologia (aceito para publicação em 21 de janeiro de 2013). No prelo.

PAULSEN, O. M. et al. Collection of domestic waste. Review of occupational health problems and their possible causes. The Science of the Total Environment, v. 170, p. 1-19, 1995.

PICOLOTO, D.; SILVEIRA, E. Prevalência de sintomas osteomusculares e fatores associados em trabalhadores de uma indústria metalúrgica de Canoas - RS. Ciência e Saúde coletiva, v. 13, n. 2, p. 507-516, 2008.

PINHEIRO, F. A.; TRÓCCOLI, B. T.; PAZ, M. G. T. Preditores Psicossociais de Sintomas Osteomusculares: A Importância das Relações de Mediação e Moderação. Psicologia: Reflexão \& Crítica, v. 19, n. 1, p. 142-150, 2006.

PUNNETT, L.; WEGMAN, D. H. Work-related musculoskeletal disorders: the epidemiologic evidence and the debate. Journal of Electromyography and Kinesiology, v. 14, n. 1, p. 13-23, 2004.

ROBAZZI, M. L. C. C. et al. Algumas considerações sobre o trabalho dos coletores de lixo. Revista Brasileira de Saúde Ocupacional, v. 20, n. 76, p. 34-41, 1994.

SANTOS, C. C. Reestruturação produtiva do setor de limpeza urbana de Salvador: repercussões sobre o trabalhador. 2011. Dissertação (Mestrado) Universidade Católica do Salvador, 2011.

SANTOS, C. O. M. et al. Desregulamentação do trabalho e desregulação da atividade: o caso da terceirização da limpeza urbana e o trabalho dos garis. Produção, v. 19, n. 1, p. 202-213, 2009.

SILVANY NETO, A. M. Bioestatística sem segredos. Salvador, 2008. 321p.

SMITH, D. R. et al. Musculoskeletal Disorders among Professional Nurses in Mainland China. Journal of Professional Nursing, v. 20, n. 6, p. 390-395, 2004. 
SPURGEON, A.; GOMPERTS, D.; HARRINGTON, J. M. Modifiers of non-especific symptoms in occupational and environmental syndromes. Occup Helth Med, v. 53, p. 361-366, 1996.

STRASAK, A. M. et al. Statistical errors in medical research - a review of common pitfalls. Swiss Med Wkl, v. 137, p. 44-49, 2007.

STRAZDINS, L.; BAMMER, G. Women, work and musculoskeletal health. Social Science and Medicine, v. 58, p. 997-1005, 2004.

TOOMINGAS, A. et al. Associations between self-rated and psychosocial work conditions and musculoskeletal symptoms and signs. Scandinavian Journal of Work, Environment and Health, v. 23, p. 130-139, 1997.

VASCONCELOS, R. C. et al. Aspectos de complexidade do trabalho de coletores de lixo domiciliar: a gestão da variabilidade do trabalho na rua. Gestão \& Produção, v. 15, n. 2, p. 407-419, 2008.

VELLOSO, M. P. Os restos na história: percepções sobre resíduos. Ciência \& Saúde Coletiva, v. 13, n. 6, p. 1953-1964, 2008.

VELLOSO, M. P.; SANTOS, E. M.; ANJOS, L. A. Processo de trabalho e acidentes de trabalho em coletores de lixo domiciliar na cidade do Rio de Janeiro, Brasil. Caderno de Saúde Pública, v. 13, n. 4, p. 693-700, 1997. WOODS, V. Work-related musculoskeletal health and social support. Occupational Medicine, v. 55, p. 177-189, 2005. 